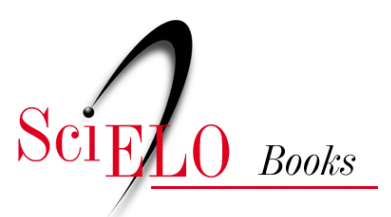

\title{
21 Tribo Helenieae Lindl.
}

\author{
Maria Alves \\ João Bernardo de A. Bringel Jr. \\ Mara Angelina Galvão Magenta
}

ALVES, M., BRINGEL JR., J.B.A., and MAGENTA, M.A.G. Tribo Helenieae Lindl. In: ROQUE, N. TELES, A.M., and NAKAJIMA, J.N., comp. A família Asteraceae no Brasil: classificação e diversidade [online]. Salvador: EDUFBA, 2017, pp. 161-164. ISBN: 978-85-232-1999-4.

https://doi.org/10.7476/9788523219994.0023.

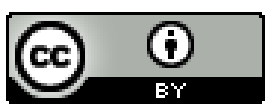

All the contents of this work, except where otherwise noted, is licensed under a Creative Commons Attribution 4.0 International license.

Todo o conteúdo deste trabalho, exceto quando houver ressalva, é publicado sob a licença Creative Commons Atribição 4.0.

Todo el contenido de esta obra, excepto donde se indique lo contrario, está bajo licencia de la licencia Creative Commons Reconocimento 4.0. 


\section{TRIBO HELENIEAE LINDL.}

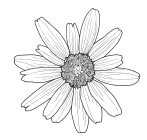

Maria Alves

João Bernardo de A. Bringel Jr.

Mara Angelina Galvão Magenta

Bentham (1873) reuniu na tribo Helenieae ("Helenioideae") todos os gêneros que possuíam receptáculo epaleáceo e pápus de páleas, que antes pertenciam a Heliantheae sensu Cassini (1819). Helenieae foi considerada por diversos autores (CRONQUIST, 1955; STUESSY, 1977; TURNER; POWELL, 1977, ROBINSON, 1981) como um conjunto não natural de gêneros, o que resultou na inserção desses táxons em várias tribos, principalmente Heliantheae e Senecioneae. Posteriormente, através de estudos moleculares (BALDWIN; WESSA, 2000, BALDWIN; WESSA; PANERO, 2002), Helenieae foi recircunscrita em 5 subtribos, incluindo 13 gêneros que correspondem às subtribos Gaillardinae e Marshallinae de Heliantheae sensu Robinson (1981). O tratamento taxonômico para a tribo, com chaves e descrição dos gêneros, foi apresentado por Panero (2007). Segundo esse autor, a maioria das Helenieae pode ser distinguida dos outros táxons da Aliança Heliantheae por não possuir cipselas enegrecidas, e sim com ráfides em suas células epidermais, e por, geralmente, apresentar folhas alternas, flores do raio com ápice do limbo conspicuamente trilobado, ramos do estilete truncados e pápus de páleas.

Helenieae possui, atualmente, 13 gêneros e cerca de 120 espécies, distribuídas no norte e no sul do continente americano, com a maior parte das espécies no sudoeste dos Estados Unidos e norte do México (PANERO, 2007). 


\section{Descrição}

Ervas bianuais, anuais ou perenes, raramente arbustos. Folhas alternas, raramente opostas, às vezes em rosetas basais, pecioladas, subsésseis ou sésseis, lâmina foliar inteira a pinatissecta, linear a lanceolada, raramente ovada, glabra a densamente lanosa. Capitulescência terminal, escaposa ou em cimeiras paniculiformes ou corimbiformes. Capítulos radiados ou discoides, invólucro cilíndrico, campanulado ou hemisférico; brácteas involucrais em 2-várias séries, subiguais ou gradativamente maiores, às vezes reflexas na antese; receptáculo plano a convexo, cônico ou globoso, geralmente epaleáceo. Flores do raio férteis ou neutras, geralmente com 3-5 lacínias; flores do disco bissexuais, raramente funcionalmente estaminadas, corolas tubulares a campanuladas, glabrescentes a densamente pubescentes; anteras curtamente caudadas a ecaudadas, apêndices do conectivo estreitamente ovados a arredondados e fortemente carenados; estilete geralmente truncado com um tufo de papilas, às vezes com um apêndice cônico, vascularizado (Balduina, Gaillardia) ou com uma proliferação de células que formam um ápice obtuso. Cipselas do raio e do disco homomórficas, clavadas a subcilíndricas, com ráfides nas células epidermais, glabras a seríceas; pápus cerdoso, cerdas livres ou fundidas, ou paleáceo, páleas oblongas, ovadas, obtusas, erosas, aristadas ou acuminadas, raramente sem pápus.

No Brasil, Helenieae está representada por 3 gêneros, Hymenoxys Cass. (2 spp.), Gaillardia Foug. (2 spp.) e Helenium L. (1 spp.).

\section{Chave de identificação para os gêneros de Helenieae no Brasil}

1. Lâminas foliares pinatissectas e alternas ao longo do caule; receptáculo plano ou cônico Hymenoxys 1'. Lâminas foliares inteiras; quando pinatissectas, formam rosetas basais; receptáculo convexo, subgloboso ou globoso 
2. Receptáculo alveolado, geralmente com projeções (Figura 13M); pápus com 6-9 páleas finas, com nervura central que excede a pálea, formando uma arista (Figura $13 \mathrm{~N}$ ). Gaillardia 2'. Receptáculo liso; pápus com 5 páleas acuminadas ou curto-aristadas ..... Helenium

\section{Literatura recomendada}

BAKER, J. G. Hymenoxys.. In: MARTIUS, C. P. von; EICHLER, A. W. (Ed.). Flora Brasiliensis. Leipzig: F. Fleischer, 1884. v. 6, pt. 3, p. 277-278.

BALDWIN, B. G.; WESSA, B. L. Phylogenetic placement of Pelucha and new subtribes in Helenieae sensu stricto (Compositae). Systematic Botany, Kent, v. 25, n. 3, p. 522-538, 2000.

BALDWIN, B. G.; WESSA, B. L; PANERO, J. L. Nuclear rDNA evidence for major lineages of helenioid Heliantheae (Compositae). Systematic Botany, Kent, v. 27, n. 1, p. 161-198, 2002.

BENTHAM, G. Notes on the classification, history and geographical distribution of Compositae. Journal of the Linnean Society Botany, London, v. 13, n. 70/72, p. 335-577, 1873.

BIDDULPH, S. F. A revision of the genus Gaillardia. Research Studies of the State College of Washington, Washington, v. 12, p. 195-256, 1944.

BIERNER, M. W. Taxonomy of Helenium Sect. Tetrodus and a conspectus of North American Helenium (Compositae). Brittonia, New York, v. 24, n. 4, p. 331-335, 1972.

CARNEIRO, C. R.; RITTER, M. R. A tribo Helenieae Benth. \& Hook. s. s. (Asteraceae) no sul do Brasil. Revista Brasileira de Biociências, Porto Alegre, v. 15, n. 1, p. 7-18, 2017.

CASSINI, H. Suit du Sixième mémoire sur la famille des Synanthérées, contenant les caractères des tribus. Journal de Physique, de Chimie, d'Histoire Naturelle et des Arts, Paris, t. 88, p. 150-163, 1819. 
CRONQUIST, A. J. Phylogeny and taxonomy of the Compositae. American Midland Naturalist, Notre Dame, v. 53, p. 478-511, 1955.

MARLOWE, K.; HUFFORD, L. Taxonomy and biogeography of Gaillardia (Asteraceae): A Phylogenetic Analysis. Systematic Botany, Kent, v. 32, n. 1, p. 208-226, 2007.

PANERO, J. L. Tribe Helenieae Cass. In: KUBITZKI, K. (Ed.). The Families and Genera of Vascular Plant: v. VIII: Flowering Plants Eudicots: Asterales. Berlin: Springer-Verlag, 2007. p. 400-406.

ROBINSON, H. A revision of the tribal and subtribal limits of the Heliantheae (Asteraceae). Washington: Smithsonian Institution Press, 1981. (Smithsonian Contributions to Botany, v. 51).

STUESSY, T. F. Heliantheae - systematic review. In: HARBORNE, J.; TURNER, B. L; HEYWOOD, V. (Ed.). The biology and chemistry of the Compositae. London: Academic Press, 1977. v. 2, p. 621-671.

TURNER, B. L.; POWELL, A. M. Helenieae - systematic review. In: HARBORNE, J.; TURNER, B. L; HEYWOOD, V. (Ed.). The biology and chemistry of the Compositae. London: Academic Press, 1977. p. 699-737.

TURNER, B. L.; WHALEN M. Taxonomic study of Gaillardia pulchella (Asteraceae-Heliantheae). Wrightia, Renner, v. 5, p. 189-192, 1975. 